\title{
Proposta de parâmetros para análise de paratextos de livros traduzidos
}

\author{
Teresa Dias Carneiro*
}

\section{Introdução}

Aproveitando o mote deste dossiê temático da Tradução em Revista - "Tradução em Movimento" - proponho-me a pensar o paratexto do livro traduzido como instância que desvela o caráter instável e culturalmente marcado de todo o material que acompanha o texto no produto livro, "aquilo por meio de que um texto se torna livro e se propõe como tal a seus leitores" (Genette, 2009, p. 9), resultado da "viagem" empreendida de uma língua-cultura para outra, tornando esse texto presente e apto para sua recepção e seu consumo no sistema meta. A "viagem" de uma língua-cultura para outra deixa marcas e traços palpáveis na publicação. O texto se despe de todo o aparato paratextual que o revestia no sistema de origem e assume nova roupagem para entrar triunfante (porque derridianamente sobrevivente) no novo sistema meta, e influenciar sua recepção. A tradução em movimento implica decisões editoriais tomadas na nova "casa", consubstanciando-se num aparato paratextual renovado. $\mathrm{O}$ verso da folha de rosto é, no livro traduzido, o relato sucinto dessa viagem, pois lá constam informações do ponto de partida (título e editora original) e do ponto de destino (título traduzido, nome do tradutor e editora da tradução).

Já na época da minha pesquisa de Mestrado (Letras/Ciência da Literatura, UFRJ-1999), que deu origem à dissertação intitulada As obras de Mário de Andrade traduzidas na França: história, concepção e crítica - em que me propus a analisar não só texto, como também o paratexto dessas obras - surpreendi-me com a incipiente bibliografia sobre o paratexto do livro traduzido dentro da teoria geral do paratexto. Os escritos teóricos

\footnotetext{
${ }^{*}$ Universidade Federal do Rio de Janeiro.
} 
existentes sobre esse assunto em geral não se debruçam sobre a especificidade do paratexto de obras traduzidas, mas sim sobre o de obras originais. É por essa vertente que discorrem Gérard Genette (2009), Antoine Compagnon (1979), Henri Mitterand (1980), Geneviève Idt (1977) e Jacques Derrida (1972 e 2002). Os poucos trabalhos que tratam do paratexto do livro traduzido são eminentemente aplicados e não teóricos, o que me despertou para um campo de investigação importante praticamente inexplorado naquele momento e ainda hoje.

Contudo, observou-se nesse lapso de tempo de 16 anos (de 1999 a 2015) um aumento do interesse acadêmico em pesquisas empíricas em paratextos de livros traduzidos, dando origem a dissertações de Mestrado e teses de Doutorado que analisam traduções e seus paratextos, ou somente seus paratextos. Por não existir um estudo formal mais cabal sobre o paratexto do livro traduzido até o momento, ao que me é dado saber, decidi, em minha tese de Doutorado, intitulada Contribuições para uma teoria do paratexto do livro traduzido: caso das traduções de obras literárias francesas no Brasil a partir de meados do século XX, (Estudos da Linguagem, PUC-Rio, 2014), ${ }^{1}$ fazer um esforço de teorização para depreender alguns parâmetros para a análise de elementos paratextuais que distinguem o livro traduzido do livro original, isto é, o prefácio de tradutor e a posição do nome do tradutor na publicação. ${ }^{2}$

Minha contribuição teórica surgiu a partir da observação e da leitura de elementos paratextuais, principalmente prefácios de tradutor, de um corpus de obras literárias francesas traduzidas no Brasil e publicadas a partir de meados do século XX até início dos anos 2000. O corpus (360 exemplares no total, podendo constar mais de uma edição de um mesmo título, principalmente de autores clássicos) foi compilado primordialmente na Biblioteca Nacional e, secundariamente, em acervo próprio originalmente existente ou adquirido conforme descobertas mais recentes em livrarias. No

\footnotetext{
${ }^{1}$ http://www2.dbd.puc-rio.br/pergamum/tesesabertas/1012062_2014_completo.pdf

2 Minha pesquisa e a tese de doutorado resultante não contemplaram as notas de rodapé do tradutor, por estarem estas diretamente ligadas ao texto, mesmo que espacialmente destacadas. Como minha intenção não era analisar os textos das traduções, mas sim principalmente prefácios de tradutor, as notas de rodapé do tradutor ficaram de fora da análise. Também não analisei glossários elaborados pelos tradutores, pelo mesmo motivo (o que estarem intimamente ligados ao texto traduzido).
} 
acervo da Biblioteca Nacional, o trabalho de levantamento foi empreendido da seguinte forma: 1 . determinação de uma lista de autores clássicos da literatura francesa dos séculos XVIII, XIX e XX; 2. busca nas referências bibliográficas, em entradas por autor, nos computadores da Biblioteca Nacional, na seção de obras gerais, a partir da lista descrita anteriormente; 3. levantamento por autor das obras traduzidas; 4 . busca e manuseio das obras do levantamento; 5. transcrição em arquivo eletrônico dos trechos encontrados nos prefácios/posfácios de tradutores falando da sua tradução, além de anotações gerais sobre a posição do nome do tradutor e a apresentação do tradutor na obra.

Abaixo, apresento então algumas contribuições teóricas que podem servir para outros pesquisadores que desejem se debruçar sobre paratextos de livros traduzidos.

\section{O nome do tradutor}

Genette, em sua obra teórica seminal sobre paratextos, intitulada Seuils, ${ }^{3}$ opta por não se deter nos elementos paratextuais ligados em termos específicos à tradução - atendo-se unicamente aos elementos paratextuais de obras originais - , como a existência e posição do nome do tradutor, se o texto é ou não apresentado como uma tradução (ou como adaptação, imitação etc.) e outros sinais de tradução (como o prefácio de tradutor e notas do tradutor), apesar de serem partes evidentes do paratexto do livro traduzido. Mesmo fazendo essa ressalva, as perguntas gerais que ele propõe para definir um elemento do paratexto continuam valendo e levantando pontos esclarecedores para a análise desses elementos paratextuais específicos. São elas: lugar do elemento paratextual (onde?), sua data de aparecimento e às vezes de desaparecimento (quando?), seu modo de existência, verbal ou outro (como?), as características de sua instância de comunicação, destinador e destinatário (de quem? a quem?) e as funções que animam sua mensagem (para fazer o quê?) (Genette, 2009, p. 12).

Ao observar o lugar e a posição do nome do tradutor na obra traduzida, a primeira pergunta (onde?) é de vital importância. Em relação ao li-

\footnotetext{
3 Traduzida no Brasil com o título Paratextos editoriais, por Álvaro Faleiros.
} 
vro traduzido, a obrigatoriedade legal de localização do nome do tradutor, no Brasil, é na ficha catalográfica. ${ }^{4}$ Qualquer outra localização é determinada pelo editor ou pelas regras da coleção, que, em última instância, derivam de decisões editoriais. O fato de o nome do tradutor constar na página de rosto já é uma benesse, que dirá constar na capa. Tal como em relação ao nome do autor, a localização do nome do tradutor com destaque maior ou menor (em local mais visível e/ou com tipo maior) depende de sua notoriedade, que pode ser acadêmica (o fato de ser professor universitário, ter títulos de pós-graduação ou ser especialista naquele autor ou obra) ou autoral (o fato de ter obras publicadas em seu nome). Tradutores-escritores recebem bem mais destaque na capa do que os tradutores profissionais não escritores, ou mesmo tradutores acadêmicos. No caso dos tradutoresescritores, o profissional empresta uma identidade e uma fama em destaque a serviço do livro, para fins midiáticos. Em suma, o destaque do nome do tradutor-escritor famoso ajuda a vender o livro, sendo do interesse dos editores que ele apareça. Se o tradutor for um ilustre desconhecido para o público em geral - mesmo que seja um profissional conhecido no mercado de tradução - , seu nome em destaque seria uma prática inútil e contraproducente. $\mathrm{O}$ nome do tradutor famoso avaliza a qualidade da tradução e o editor atua como abonador do tradutor, assim como o é do autor, pois o introduz e nomeia, dando-lhe o destaque devido à sua posição. Essa posição destacada pode ser reforçada por menções a afiliações acadêmicas ou graus e funções universitárias, além de menções a outros livros traduzidos ou escritos pelo tradutor. No corpus analisado, chegou-se a ver casos de existência de minicurrículos dos tradutores, com essas menções constando nas orelhas ou em páginas separadas.

Assim sendo, com base nas observações realizadas em relação ao lugar e à posição do nome do tradutor na obra traduzida, depreendi uma hierarquização, em ordem decrescente de importância:

1. na capa (junto ou abaixo do nome do autor, normalmente em fonte menor);

2. na contracapa;

\footnotetext{
${ }^{4} \mathrm{Na}$ tese, no Capítulo 3, item 3.2, faço um histórico das leis de direitos autorais e, nelas, da obrigatoriedade de constar o nome do tradutor na obra traduzida, no Brasil.
} 
3. nas orelhas;

4. na folha de rosto ou folhas iniciais;

5. no verso da folha de rosto (página de créditos);

6. na ficha catalográfica;

7. não consta.

A hierarquização da posição do nome do tradutor na obra traduzida proposta acima foi regida por critérios de visibilidade de leitura. Ainda nas livrarias ou nas bibliotecas, o leitor em primeiro lugar é atraído pelos dizeres da capa, quarta capa e orelhas, nesta ordem. São estes os elementos paratextuais com forte carga publicitária e imagética. Toda a arte de capa é trabalho de designers cada vez mais especializados, que procuram trazer para o invólucro elementos significativos do miolo, empreendendo um pequeno resumo apelativo por meio de imagens e diagramação. O nome do tradutor na capa, e sequencialmente na quarta capa e nas orelhas, passa a fazer parte de todo esse apelo artístico e publicitário que envolve a programação visual das capas, conferindo-lhe uma maior projeção e maior destaque. No Brasil, ainda é considerado raro constar o nome do tradutor na capa, prática bem mais comum nas obras literárias traduzidas na França, por exemplo, mesmo que esse tradutor não seja um autor ou poeta de renome, mas que, por sua atividade tradutória, tenha construído uma reputação de bom profissional.

Depois de apreciar a capa e a quarta capa, o leitor normalmente abre o livro em suas primeiras folhas. Se nelas constar o nome do tradutor, é mais uma oportunidade para que atente para quem foi que o traduziu. Por fim, no verso da folha de rosto, o nome do tradutor pode constar nos créditos acima da ficha catalográfica e necessariamente nesta. Desde 1998, a inexistência do nome do tradutor na obra traduzida é bem mais rara, por estar em flagrante violação à Lei 9610/98, a Lei de Direitos Autorais em vigor no Brasil.

Portanto, se o pesquisador tiver interesse na observação da posição do nome do tradutor na obra traduzida, essa hierarquização pode auxiliar bastante, principalmente se a análise for feita em correlação com o status de que o tradutor goza no mercado editorial e na sociedade em geral (e se se trata de um tradutor-escritor, é claro). De forma que é possível dizer que, se 
o tradutor for também escritor (ou acadêmico de grande renome), aumentam consideravelmente suas chances de ter seu nome em posição de destaque na edição.

\section{O prefácio de tradutor}

Refiro-me aqui a "prefácios" como um termo guarda-chuva, incluindo também os posfácios de tradutor. Apesar de a localização antes ou depois do texto ser significativa, os prefácios ou posfácios se distinguem pouco em seu teor. Pode-se dizer que, via de regra, o prefácio/posfácio do tradutor é escrito após a tradução, mesmo que posicionado antes dela na publicação, no caso dos prefácios. Isso mostra claramente que a sequência dos elementos na edição não corresponde necessariamente a uma sequência cronológica de elaboração dos elementos. Os elementos paratextuais são instáveis e podem surgir e desaparecer de uma edição para outra, mesmo em se tratando de obras originais. E ainda, mesmo que o prefácio/posfácio de tradutor trate de seu projeto tradutório (projeto é sempre algo a ser realizado), esse projeto já se consubstanciou em uma tradução concreta, deixando de ser um projeto stricto sensu. Portanto, percebe-se que os prefácios de tradutor contêm muitas justificativas e elementos exculpatórios típicos de quem já fez (e acha que talvez não tenha feito tão bem assim) e não de quem ainda fará.

De modo geral, os prefácios de tradutor podem ser divididos em dois grandes grupos: 1. os prefácios que não tratam da tradução; e 2. os prefácios que tratam da tradução. Para minha surpresa, nas obras analisadas na minha pesquisa, os prefácios de tradutor que não tratam da tradução foram muito mais numerosos do que os outros e excederam as expectativas iniciais da pesquisa. Nesses, os tradutores atuam como especialistas bem informados no autor e na obra, não se diferenciando de outros estudiosos e acadêmicos. O tradutor ocuparia, nesse caso, uma função didática que poderia muito bem ter sido desempenhada por outro especialista.

Observou-se ainda grande número de recorrências nos prefácios/posfácios de tradutores. Mais do que coincidências, essas repetições podem mostrar, por um lado, que os tradutores leem os prefácios/posfácios de outros tradutores, e dialogam com eles, reafirmando posições e reite- 
rando ações. $O$ fato de terem um espaço na edição para apresentarem suas ideias poderia parecer, à primeira vista, uma boa oportunidade para os tradutores saírem das sombras e marcarem posições de valorização de seu trabalho. Porém, o que se vê na maior parte das vezes é uma repetição ad nauseam de chavões e ideias feitas que só servem para esvaziar essa oportunidade de afirmação e desperdiçar a chance de exercer uma agentividade mais comprometida com um reposicionamento social da profissão. As recorrências no gênero prefácio de tradutor reforçam a posição subserviente, falsamente humilde e pouco inovadora de seus elaboradores.

A observação de fortes recorrências nos prefácios de tradutor gerou a necessidade de recorrer a aportes teóricos oriundos da teoria dos gêneros textuais/discursivos, para ajudar a teorizar sobre os prefácios de tradutor dentro de uma teoria do paratexto do livro traduzido. A partir da categorização de John Swales que deu origem ao modelo CARS (acrônimo de Create A Research Space), elaborado com base em um corpus de introduções de artigos científicos (HEMAIS \& BIASI-RODRIGUES, 2005, p. 120-127) e tomando por base um desenvolvimento em movimentos e passos, elaborei uma proposta de movimentos e passos prototípicos nos prefácios de tradutor. Os movimentos e passos abaixo foram depreendidos da leitura dos prefácios recolhidos na pesquisa, em uma sequência lógica. Contudo, na análise de casos concretos, verificou-se que os prefácios de tradutor nem sempre apresentam todos esses itens e, mesmo quando os apresentam, nem sempre seguem a sequência apontada. Os movimentos e passos abaixo, portanto, devem ser encarados como uma linha mestra da análise e não como uma prescrição rígida.

MOVIMENTO 1 - APRESENTAÇÃO DA EDIÇÃO

MOVIMENTO 2 - BIOGRAFIA DO(S) AUTOR(ES)

Passo 2A - Fatos histórico-biográficos

Passo 2B - Escola literária de pertencimento

Passo 2C - Fontes e influências

MOVIMENTO 3 - O CONJUNTO DA OBRA E A OBRA ESPECÍFICA

Passo 3A - Significado da obra específica no conjunto da obra

Passo 3B - Análise literária (estilo, temas, construção literária) 
Passo 3C - Exemplos concretos

MOVIMENTO 4 - DIFICULDADES / PECULIARIDADES DA

TRADUÇÃO

Passo 4A - Exemplos concretos

MOVIMENTO 5 - JUSTIFICATIVAS PARA O PROJETO TRADUTÓRIO

Passo 5A - Descrição do projeto tradutório

Passo 5B - Contribuições teóricas

Passo 5C - Possíveis deficiências da tradução

Passo 5D - Perspectiva humilde, com ou sem pedido de desculpas

Um exemplo retirado do corpus de pesquisa é o prefácio de André Teles e Rodrigo Lacerda para a tradução de O conde de Monte Cristo, publicada pela Zahar em 2012.

Apesar de o livro ter sido traduzido pelos dois tradutores, o prefácio foi escrito exclusivamente por Rodrigo Lacerda, conforme dito em entrevista transcrita em sua página na Internet (www.rodrigolacerda.com.br), onde também descreve o método de tradução a dois. Nessa entrevista, Rodrigo conta que André Teles fez a primeira versão da tradução, depois, ele, Rodrigo, cotejou linha a linha com os textos em francês, traduzindo os saltos, tirando dúvidas, homogeneizando o texto, refazendo a pontuação. Depois André aprovava ou não as sugestões de Rodrigo. Finalmente, entraram na fase dos ajustes finais de padronização. No momento da edição, enquanto Rodrigo escrevia a apresentação, André selecionava as ilustrações. Este prefácio, intitulado Apresentação, é uma versão resumida da apresentação contida na edição em formato padrão (esta edição é em formato de bolso).

Neste prefácio, Rodrigo descreve fatos histórico-biográficos (Movimento 2), a construção literária (Movimento 3), apresenta a edição (Movimento 1) e fala brevemente sobre o projeto tradutório (Movimento 5). 


\section{Apresentação}

O conde de Monte Cristo foi publicado originalmente como folhetim, entre agosto de 1844 e janeiro de 1846. No Brasil, já em 1845 (isto é, com apenas alguns meses de atraso em relação à França), saía no Jornal do Commercio com grande sucesso.

É consenso entre os críticos que o livro faz um retrato bastante fiel da França nos primórdios da democracia, juntamente com a Comédia humana, de Balzac, Os mistérios de Paris, de Eugène Sue, e Os miseráveis, de Victor Hugo. Aqui, esse retrato amplo da sociedade é possibilitado pela trajetória do protagonista Edmond Dantès, que parte de uma posição social intermediária, desce às profundezas quando é preso injustamente e alcança o topo da pirâmide quando escapa da prisão e enriquece.

À medida que Dantès marcha para a vingança, distancia-se dos homens comuns e oferece a leitores de todos os tempos um pouco de redenção: a revanche da justiça legal, a reinstauração da ordem moral. Ninguém pode lhe negar que, realmente, faz de tudo para obtê-las. Ao suspense intrínseco ao tema - "Ele vai conseguir se vingar?" (no fundo intuímos que vai) -, soma-se o suspense maior: "Qual será sua vingança?"

Dumas trabalhava em colaboração com dezenas de outros escritores e pesquisadores. $\mathrm{O}$ único de seus assistentes a realmente chegar perto de uma coautoria foi Auguste Maquet (1813-88), com quem Dumas trabalhou em cerca de vinte romances, inclusive $O$ conde de Monte Cristo.

Tudo indica que Maquet, ex-professor universitário, redigia um primeiro esboço a partir

\section{MOVIMENTO 2}

Passo 2A - fatos histórico-biográficos

\section{MOVIMENTO 3}

Passo 3B - construção literária

\section{MOVIMENTO 2}

Passo 2A - fatos histórico-biográficos 
de seus conhecimentos históricos e pesquisas. Em seguida, este era reescrito por Dumas, que acrescentava seu estilo romanesco e autêntico jorro de imaginação. O texto final foi sempre de Dumas - e não por acaso, quando a dupla se desfez e Maquet entrou com um processo contra o parceiro, exigindo uma soma exorbitante por direitos autorais, a Justiça determinou o pagamento de royalties suplementares, mas negou-lhe o privilégio de assinar como coautor.

A presente tradução baseou-se nas melhores edições existentes: a da Pléiade, a da CalmannLévy (em seis volumes, reprodução da edição standard de 1895), a da Bouquins e a da Folio. Sem mudanças substantivas no original, adaptamos a pontuação para as normas vigentes, modernizamos com moderação as formas de tratamento e privilegiamos, sempre, a fluência da leitura. As ilustrações aqui incluídas, de autoria de Gustave Staal, entre outros, integraram a $3^{\text {a }}$ edição francesa de $O$ conde de Monte Cristo.

(Esta é uma versão reduzida da apresentaMOVIMENTO 1 Apresentação da edição

MOVIMENTO 5

Passo 5A - descrição do projeto tradutório

\section{MOVIMENTO 1}

Apresentação da edição

ção de Rodrigo Lacerda para $O$ conde de Monte Cristo: edição definitiva - comentada e ilustrada, publicado pela Zahar em 2008.)

Os prefácios de tradutor que não tratam da tradução só costumam conter os três primeiros movimentos, sendo os dois últimos reservados para os prefácios de tradutor que comentam sobre a tradução. No Movimento 4, "Dificuldades/Peculiaridades da Tradução", é muito comum aparecerem comentários sobre passagem difíceis (ou intraduzíveis) na tradução, soluções criativas para problemas de equivalências, estranhezas contidas no original e diferenças linguístico-culturais entre as línguas em conta- 
to. Não é incomum surgirem exemplos concretos específicos, com a explicação do motivo pelo qual determinada expressão foi traduzida por outra, detectando reflexões atentas. Já no Movimento 5, “Justificativas para o Projeto Tradutório", podem comparecer formulações teóricas ou manifestações de apoio a uma postura estrangeirizadora ou domesticadora, segundo as concepções de Venuti (VENUTI, 1996), mesmo que o nome do teórico não seja citado, ou concepções semelhantes a essas. Quanto às possíveis deficiências na tradução, o tradutor adianta-se a críticas que ele imagina que poderiam surgir em determinadas passagens ou soluções encontradas por ele. Tais deficiências às vezes não são deficiências de fato, mas adiantam pedidos de desculpas, nem sempre sinceros. Nestes, percebe-se uma modéstia muitas vezes mal disfarçada e um tom confessional, veiculando ou não pedidos de desculpas.

Ao descrever seu projeto tradutório ou o resultado do seu trabalho, alguns tradutores expõem sua concepção do que seja tradução para ele(a) e o conceito de fidelidade que ele(a) valida ou no qual se pauta. $\mathrm{Na}$ tese, $\mathrm{Ca}$ pítulo 2, item 2.2, "História Intelectual - conceitos de tradução e (in)fidelidade", tracei um breve histórico do conceito de tradução no Ocidente, sob o aporte teórico da História dos Conceitos, segundo Koselleck (KOSELLECK, 2006). Das mudanças percebidas no conceito, depreendi algumas posições a respeito desses conceitos que podem mais facilmente ser detectadas no discurso dos tradutores em seus prefácios. É importante, portanto, entender quais os conceitos de tradução e fidelidade sobre os quais o tradutor se apoia, mesmo que isso não esteja totalmente explícito no prefácio do tradutor. Para isso, é bastante produtivo conhecer dados importantes da biografia do tradutor, de molde a "classificá-lo" numa das seguintes categorias: tradutor-escritor, tradutor-acadêmico e tradutor profissional. Para tanto, na tese, foi eleita a principal fonte de pesquisa o DITRA - Dicionário de Tradutores Literários no Brasil. Segundo informações constantes no site na Internet ${ }^{5}$, um dicionário que constituiu um desdobramento do projeto integrado Tradução, Tradição e Inovação: o papel das traduções do alemão, espanhol, francês, italiano e latim no sistema literário brasileiro (1970-2005),

\footnotetext{
${ }^{5}$ http://www.dicionariodetradutores.ufsc.br/pt/index.htm.
} 
do Grupo de Pesquisa Literatura Traduzida, com objetivo de fazer um levantamento dos tradutores literários no Brasil e traçar o seu perfil. O projeto, aprovado pelo CNPq, contou com pesquisadores professores e estudantes. A publicação online é de responsabilidade do Núcleo de Tradução da UFSC. Os critérios para a escolha dos tradutores incluídos nos verbetes foram inspirados nos dados do Index Translationum, da UNESCO, que compila as traduções feitas no mundo todo e que constitui o mais amplo e respeitado repertório sobre o assunto, e em pesquisas bibliográficas em bibliotecas e em sites. Vários instrumentos foram utilizados para chegarem às informações biobibliográficas dos verbetes. Além do contato direto com os tradutores, foram pesquisados a plataforma Lattes, do CNPq, e os sites da Associação Brasileira de Tradutores, do Sindicato dos Tradutores, da Câmara Brasileira do Livro, do projeto Releituras e também as listas e páginas pessoais de tradutores.

Em segundo lugar, a maior fonte de pesquisa sobre biodata dos tradutores foi a Wikipedia. Apesar de não ser um site totalmente acurado, já que funciona com base em contribuições do grande público e não em um esforço de uma instituição de pesquisa, essa enciclopédia virtual sofre críticas e reparos de especialistas que podem não concordar com as informações contidas nos verbetes, propondo-se a aperfeiçoá-las. Além da Wikipedia, muitas informações podem ser obtidas em sites de editoras e páginas pessoais dos tradutores.

Importante também é depreender da biografia dos tradutores se estes foram expostos ou não à teoria da tradução, pois isso pode ajudar a entender sua concepção dos conceitos em questão, o de tradução e o de fidelidade. Após serem levantadas todas as informações pertinentes, é possível fazer uma análise dos prefácios, como a que se fez na tese, no Capítulo 5, "Análise de Dados".

\section{Conclusões finais}

Com base no exposto, percebe-se que a teoria dos gêneros textuais/discursivos serve de base para estudar as regularidades e recorrências nesse gênero, mas a análise dos conceitos de fidelidade e tradução, a percepção dos pontos de contato entre teoria e prática e o destaque dado ao 
nome do tradutor na edição - frequentemente refletindo sua posição de destaque/apagamento na sociedade - podem servir como rota para analisar o que se diferencia em cada prefácio/posfácio de tradutor.

Em última instância, o que distingue o paratexto do livro traduzido do paratexto do livro original são todos os elementos referentes ao tradutor e à tradução contidos na edição. Assim sendo, os pesquisadores que desejarem estudar as especificidades do paratexto do livro traduzido devem atentar para o seguinte:

1. se existem prefácios/posfácios/introduções do tradutor na edição;

2. se os elementos acima falam de tradução ou da tradução específica, e o teor dessa menção;

3. se existem outros prefácios/posfácios/introduções de outrem que falem de/da tradução e o teor dessa menção;

4. se há outras menções ao tradutor ou à tradução em outros elementos paratextuais, por exemplo, orelha, quarta capa, dados biográficos dos tradutores etc.;

5. qual é a posição do nome do tradutor: posição de destaque (capa, quarta capa), uma menção comum (folha de rosto) ou somente uma menção legal (ficha catalográfica);

6. em que medida a biografia do tradutor (que derivou a minha classificação dos tradutores na pesquisa) determina ou influencia a posição de destaque do seu nome na edição - o estudo da biografia e a visibilidade social do tradutor não têm um interesse em si mesmas, mas lançam luz à visibilidade paratextual do tradutor;

7. o estudo das notas de tradutor é um estudo que exige a leitura do texto traduzido - ou pelo menos de trechos desse texto - , enquanto que o estudo dos prefácios/posfácios não. É na leitura e análise do texto traduzido que se pode depreender a visibilidade textual do tradutor. Na pesquisa, o que me interessou foi, em primeiro lugar, a visibilidade paratextual e, em seguida, a visibilidade social no que se refere e influencia a visibilidade paratextual.

$\mathrm{Na}$ esperança de ter traçado alguns parâmetros para a análise do paratexto do livro traduzido, no que se refere especificamente aos prefácios do tradutor e à posição no nome do tradutor na edição, admito que ainda 
há muito a ser feito para se elaborar uma teoria mais completa do paratexto do livro traduzido. As minhas reflexões são somente uma contribuição introdutória ao assunto, aguardando novas contribuições, comentários e discussões.

\section{Referências}

COMPAGNON, A. Le commencement du livre et la fin de l'écriture. In La Seconde main ou le travail de la citation. Paris: Seuil, 1979, p. 341-346.

DERRIDA, J. La dissémination. Paris: Seuil, 1972.

- Torres de Babel. Trad. Junia Barreto. Belo Horizonte: Editora UFMG, 2002.

DUMAS, A. O conde de Monte Cristo. Trad. André Teles e Rodrigo Lacerda. Rio de Janeiro: Zahar, 2012.

GENETTE, G. Paratextos editoriais. Trad. Álvaro Faleiros. Cotia, SP: Ateliê Editorial, 2009.

HEMAIS, B. e BIASI-RODRIGUES, B. A proposta sociorretórica de John M. Swales para o estudo de gêneros textuais. In: MEURER, J. L.; BONINI, A. e MOTTA-ROTH, D. Gêneros: teorias, métodos, debates. São Paulo: Parábola, 2005, p. 108-129.

IDT, G. Fonction rituelle du métalangage dans les prefaces "hétérographes". Littérature, Paris, Larousse, no 27, 1977, p. 65-74.

KOSELLECK, R. História dos conceitos e história social. In Futuro passado: contribuição à semântica dos tempos históricos. Trad. Wilma Patrícia Maas e Carlos Almeida Pereira. Rio de Janeiro, Contraponto/Editora PUC-Rio, 2006, p. 97-118.

MITTERAND, H. La préface et ses lois: avant-propos romantiques. In Le Discours du roman. Paris: PUF, 980, p. 21-34.

VENUTI, L. A invisibilidade do tradutor. Trad. Carolina Alfaro de Carvalho. paLavra, no 3, 1996, p. 111-134.

Resumo: $\mathrm{O}$ presente artigo apresenta uma proposta de parâmetros para análise de paratextos de livros traduzidos, em especial, dos prefácios de tradutor. O trabalho tem como base pesquisa de doutorado realizada em 360 exemplares de obras francesas traduzidas no Brasil, de meados do sé- 
culo XX até início dos anos 2000. Por não haver uma teoria acabada sobre o assunto, a atual proposta pode ser de grande valia para pesquisadores interessados em estudar esse tipo paratextual. Também são feitas considerações sobre a posição do nome do tradutor na edição e suas implicações.

\begin{abstract}
This article proposes parameters for the analysis of paratexts in translated books, regarding in particular translator's prefaces. The work is based on a doctoral research conducted with 360 copies of French works translated in Brazil from the mid-twentieth century to the early 2000s. Since there is no comprehensive theory on the subject, this proposal may be of great value to researchers interested in studying paratexts. We also remark on the position of the translator's name on each edition and its implications.
\end{abstract}

